\title{
Chapter 2 \\ Participatory Transport Planning: The Experience of Eight European Metropolitan Regions
}

\author{
Janez Nared
}

\begin{abstract}
This chapter presents experience with participatory transport planning in eight European metropolitan regions: Ljubljana, Oslo, Gothenburg, Helsinki, Budapest, Rome, Porto and Barcelona. These metropolitan regions answered the questionnaire on strengths, weaknesses and needs and an in-depth questionnaire on participatory transport planning. The results were presented at a workshop, where representatives from these eight metropolitan regions shared their experience in two workshop sessions, one dealing with the key stakeholders in participatory transport planning and the other dealing with ways to get them involved. The findings show that stakeholder involvement differs between the local and regional levels. Participants' engagement is greater at the local level, where measures are more concrete and less abstract. The participatory planning process takes longer than the traditional planning processes, but it can ease the implementation of the project/measure to the extent that it justifies the additional resources and time. It is of crucial importance to include all the relevant stakeholders, to provide an experienced facilitator and, above all, to include the results in the final plans and policies. Although there are differences in the participatory planning culture between the countries and regions involved, the use of participatory methods in transport planning is becoming increasingly important.
\end{abstract}

Keywords Participatory planning $\cdot$ Transportation $\cdot$ Mobility $\cdot$ Metropolitan region $\cdot$ Planning system

\subsection{Introduction}

Since the 1960s, when the importance of citizen participation in planning decisions was highlighted by Jacob (1961) and Arnstein (1969), participation and participatory planning have been slowly but persistently gaining importance. These two concepts refer to the inclusion of the affected or interested population groups in forming joint decisions, in which the ones directly affected by a specific decision have the right

\section{J. Nared $(\varangle)$}

Research Centre of the Slovenian Academy of Sciences and Arts, Anton Melik Geographical Institute, Ljubljana, Slovenia

e-mail: janez.nared@zrc-sazu.si 
to participate in the decision-making process. As such, resident participation and participatory planning are the vehicles for resident empowerment and are important elements of local democracy (Pacione 2014). Participation is considered to be very powerful in sustainable development, public support of decisions and behavioural change among the populace (Sagaris 2018), and it is thus important strategic planning instrument (Rahman 2016).

Integrating the public into planning procedures is still largely lacking (Sagaris 2014; Nared et al. 2015; Hong 2018; Bissonnette et al. 2018). As observed in the Planning Democracy report (2012), despite the recognized advantages of participation and its inclusion in the legislation, people still feel it is not satisfactorily implemented in practice. Sagaris (2018) argues that convincing the residents about a project's usefulness without first considering and including the people's needs and expectations in the project most likely leads to failures in both the participatory process and the project or plan itself.

As determined by Pacione (2014), resident participation depends on the local context. In terms of metropolitan regions, participation can be discussed within the context of their governance, whereby not only residents, but also various territorial levels, sectors, institutions, and associations must be involved in managing and preparing plans. This results from the division of competences among various administrative units and sectors that often neglect integrative planning because of their own interests and partial plans. Thus, a common learning process and participative planning are of crucial importance for achieving better governance of metropolitan regions and must be supported by active involvement of institutional and non-institutional actors from entire functional area (Nared 2016). A need for a good and well-coordinated management of metropolitan regions is clearly shown in transport, which both reacts to settlement, economic development and the development of technology and defines an individual's inclusion in the social life (e.g. Özkazanç and Sönmez 2017). Therefore, transport must be coordinated with various sectors, such as spatial and economic planning, various territorial units (the metropolis and its surrounding municipalities) and the residents using the transport system.

According to Sagaris (2018, p. 8), the key challenge in this remains:

... the current lack of institutional arrangements that can consolidate these kinds of more deliberative, collaborative participatory processes, and make them a permanent part of everyday transport planning. This would simplify their implementation and generate more fundamental consensuses, based on shared visions and strong alliances of diverse, interdependent actors, in the public, citizen and private spheres.

In this regard, the role of public transport users is important because they do not always decide rationally, and so sometimes completely subjective decisions predominate. Therefore, it is vital to know their motives and patterns to improve their travelling experience as well as to direct the required transport infrastructure investment (Delclòs-Alió and Miralles-Guasch 2017). Nostikasari (2015) argues that it is important to explore how experience-based knowledge contributes to more inclusive transport planning processes.

In line with the needs discussed above, this study examines the current state of participatory transport planning in the following eight European metropolitan 
regions: Ljubljana (Slovenia), Oslo (Norway), Gothenburg (Sweden), Helsinki (Finland), Budapest (Hungary), Rome (Italy), Porto (Portugal) and Barcelona (Spain) and the findings of planners, experts and public administration representatives regarding public participation and the implementation of participatory planning processes.

\subsection{Methods}

This study is based on several years of project cooperation between eight European metropolitan regions, which, in preparing the project concept, identified participatory transport planning as an important transport and mobility challenge. Participatory transport planning was highlighted because transport and mobility strongly influence an individual's everyday life. Therefore, the participation of individuals, especially the residents of a specific city and the commuters, is key because they have a lot of experience using the transport infrastructure and public transport. This means they are the ones that provide experience-based knowledge (Nostikasari 2015) and can thus propose effective solutions. Their participation is the more important because nearly all changes on the path to more sustainable mobility demand behavioural change (Nared 2019), which is a lengthy process and can only be carried out in cooperation with the residents. The exchange of experience between the regions included was also carried out in a participatory manner.

The methodology used in this chapter is based on the following steps:

1. Analysis of the strengths, weaknesses and needs related to transport planning in individual metropolitan regions. The prepared questionnaire was completed by the representatives of the metropolitan regions, largely from offices in charge of transport planning.

2. In-depth questionnaire on perceived challenges in participatory transport planning completed by experts from each metropolitan region, either the ones in charge of transport planning within an individual region or external experts that are well-acquainted with the situation.

3. International workshop attended by the representatives of the metropolitan regions, especially from the offices in charge of transport planning, and experts that are well-acquainted with the situation in a specific region.

4. Evaluation and discussion of the findings by the project leader.

The analysis of strengths, weaknesses and needs dealt with the broader topic of transport in metropolitan regions, whereas the in-depth questionnaire included only questions related to participatory transport planning. Using the model of Bickerstaff and Walker (2002, 2005), it was divided into the following four sections:

- Open questions on participatory transport planning,

- Quantitative and qualitative assessment of an existing local/regional transport plan, 
- Good/bad practice presentation,

- Current experience-institutions' knowledge of participative processes and methods.

Because both questionnaires contained open questions, the answers provided were of varying scope and quality. In addition, due to various institutional frameworks and documents examined in detail by the representatives of individual metropolitan regions, a detailed comparison between the regions was not possible. Hence, the analysis focused on the most relevant common points that could be determined from the answers obtained.

The respondents (i.e. the representatives of the metropolitan regions) were also asked to suggest any burning issues that they might want to discuss at the workshop. These issues served as guidance for defining the intersecting topics or content discussed at the workshop.

The workshop on participatory transport planning was attended by over fifty planners, experts and public transport providers from all key metropolitan regions (Fig. 2.1). It focused on the two most relevant topics that emerged from the in-depth questionnaire on participatory transport planning:

- Whom to involve,

- How to involve them.

We dedicated one workshop session to each topic. The first part of the workshop session was a short introduction that provided some of the most relevant facts,

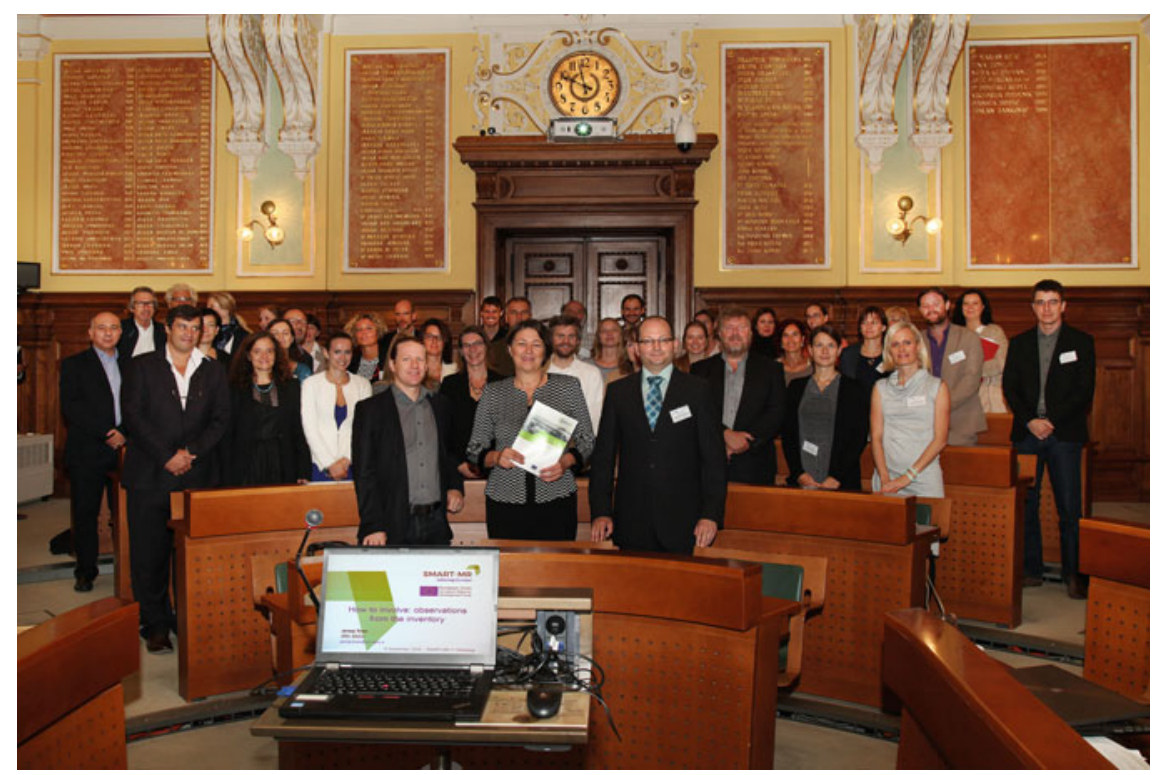

Fig. 2.1 Workshop participants with the European commissioner Mrs. Violeta Bulc. Photograph Marko Zaplatil, Archive ZRC SAZU 
experience and questions indicated in the in-depth questionnaire, as well as short presentations on good and bad practices that illustrate the most relevant aspects of the topic discussed.

After the introduction, the participants were divided into four groups. Thematically, two groups discussed one set of questions and another two groups the second set of questions. After $30 \mathrm{~min}$, the groups changed places and discussed the other set of questions. Each group was moderated by a moderator and keeper of the minutes.

During the workshop, session and afterwards the findings were summed up and presented at a plenary session by the moderator, who led the two groups' discussion. The presentation was continued by the next moderator, who discussed the same set of questions by another two groups. The findings were jointly compared and thoroughly discussed at a plenary session, where the main conclusions were drawn. The same was done with the findings for the second set of questions.

The workshop was followed by a detailed analysis of all the findings and a comparison of these with the findings of other authors.

\subsection{Results}

\subsubsection{Analysis of Strengths, Weaknesses and Needs}

The analysis highlighted the importance of participatory transport planning, something all the metropolitan regions included are aware of. However, it turned out that the Scandinavian metropolitan regions had much greater experience in actually implementing the participatory process. All three Scandinavian metropolitan regions (i.e. Oslo, Gothenburg and Helsinki) have a longer participatory planning tradition and well-established mechanisms for including key stakeholders and target groups, which is reflected in a greater awareness of residents and institutional stakeholders, greater trust in open and accessible administration, and a greater objectivity of views on unresolved challenges because anyone interested in the matter is also acquainted with the opposing viewpoints.

A pro forma definition of participatory planning in the relevant legislation is typical of the other five metropolitan regions, where participatory planning usually appears in the form of public disclosures, specific online tools for obtaining resident or user opinion and including various stakeholders as part of individual projects and prior initiatives for greater participation in planning.

Regardless of their varied experience with participatory transport planning to date, what all metropolitan regions have in common is that participatory planning still has the potential to be used much more, but the responsible institutions rarely utilize it within a greater scope than that prescribed by law. It often occurs too late in the planning process and even then, it is used more to provide information than to actually involve the relevant public. This may be the result of highly centralized decision-making, which views numerous transport and spatial planning actors as 
obstacles in making decisions, or overlapping areas of responsibility, which, due to the absence of a coordinator and ineffective cooperation between various sectors, the public and private spheres and with the wider population, institutions do not resolve together, preferring to focus on areas they are more familiar with and on legally defined responsibilities. Participatory planning is also hindered by a lack of data, unfamiliarity with appropriate communication tools and often fear that the participatory process will result in criticism of the current system rather than effective planning solutions.

According to the respondents, participation should be seen as a process that provides new insights, makes the plan more robust and brings better results. This demands consistent inclusion of participatory planning at all territorial levels (from the local to the state level) and in all thematic areas, and constructive cooperation between all responsible stakeholders (sectors, public and private sector, transport providers, residents, etc.). To enhance participatory planning, it is also necessary to prepare suitable communication platforms (including ICT, social media, interactive maps), train the facilitators and raise the awareness of the participatory planning modes and methods.

\subsubsection{Regional Aspects of Participatory Transport Planning (In-Depth Questionnaire)}

The partners also addressed in greater detail the questions from the analysis of strengths, weaknesses and needs with an in-depth analysis of participatory transport planning in the metropolitan regions.

In the regions included, the legislative requirement for public participation was most often identified in relation to spatial planning (planning, land-use, building acts and environmental impact assessment acts), whereas the situation in transport legislation varied by region. Thus, participation in standard transport planning is still very limited (e.g. in Slovenia), whereas the situation is much better in relation to sustainable urban mobility plans because it follows the Eltis guidelines (2014).

In identifying key transport planning stakeholders, the overlapping of institutions in charge of individual spatial planning segments is evident. Responsibilities are often divided among various administrative levels (e.g. the state is in charge of state roads and railway infrastructure, the region is responsible for regional roads and the municipalities are responsible for local roads) and various agencies and offices, and as a rule, there is also great variety among transport providers. Some regions highlight the management aspect of transport and focus on the areas of responsibility of an individual body, whereas others (e.g. Rome) focus on passengers, major employers and owners of transport operators (e.g. passengers or freight users seeking low prices/costs and reliable, safe, predictable journeys, operators minimizing costs and maximizing profits, owners (i.e. shareholders) seeking maximum profits, dividends and growth, etc.). 
Each set of stakeholders depends on the specific regional governance structure and the planning level or goals, whereby, for instance, national projects have different stakeholders than local projects.

A decisive role in directing the participatory process is also played by stakeholders that can shape public opinion or acquire greater influence within the process. In most regions, the predominant influence is exerted by politicians (Gothenburg, Helsinki, Rome and Porto), transport operators and sectorial leaders that use extensive knowledge to gain benefits for their company or sector (Ljubljana, Budapest and partly Oslo). Other frequently listed influential actors include the media (Gothenburg, Helsinki and Barcelona) and transport-related NGOs (Oslo, Helsinki, Budapest and Barcelona).

In Scandinavian countries, the participation of NGOs takes place via established formal consultations during public disclosures; they also often participate at conferences and workshops (Ljubljana, Oslo, Budapest, Rome and Porto). In general, the metropolitan regions included in the project communicate with NGOs through the media, web pages, e-mail or face-to-face contacts. In Barcelona, NGOs participate in the mobility council, which includes all formal and informal stakeholders related to mobility in the Barcelona metropolitan area. The mobility council meets at least twice a year and presents various ways of working (sectoral working groups, seminars, conferences, etc.). This council includes the main actors of civil society (professional associations, social and environmental associations, universities, etc.).

Six of the eight metropolitan regions have direct participatory planning experience. Considering the project topic, it is understandable that the majority of partners used the participatory process in producing mobility plans, transport plans and strategies, documents closely related to this (e.g. strategic documents at the regional level, such as urban, development or spatial plans and land-use plans) or documents addressing climate change and air quality.

A broader work group was usually established to carry out the participatory process. Alongside the partners of the institutions included in the project, it also involved external experts, who often led the participation process.

The use of individual methods was always adapted to the relevant needs. The most frequently used method was workshops, followed by public meetings, online platforms for submitting opinions and various questionnaires, work groups and meetings. Great emphasis was also placed on communication with the residents because the respondents often highlighted the use and analysis of online social networks and communicating messages through the media, websites and newsletters.

Despite experience with carrying out participatory planning, there are still many open questions, such as how to tackle this type of planning and how to ensure its credibility and validity. Among these, the following should be highlighted:

- How can the opinions of various stakeholders be captured in long-term strategic planning, taking into account the number of stakeholders included and the variety of initiatives and expectations?

- How can the predominance of specific sectors or stronger/more active stakeholders be prevented? 
- How can residents' expectations be included in the plans?

- How can the interest and participation of stakeholders be maintained in lengthy planning processes, accounting for the need for frequent stakeholder participation?

- How can credibility and legitimacy be maintained in cases when the plan cannot take into account the residents' wishes because of financial, technical or any other circumstances?

- How can more vulnerable groups be involved, especially if prior knowledge is required (e.g. the use of online tools by the elderly, children and financially weaker groups)?

- How can the participatory process address unattractive, but necessary measures?

These questions were partly answered at the workshop.

\subsubsection{Workshop Results}

As the analyses conducted before the workshop showed, all the metropolitan regions were aware of the importance of participatory transport planning, as well as its difficulty and challenges. These are connected with the planning level (local, regional or state), activity (strategic or implementing) and the number and nature of stakeholders that need to be included in the process. Regardless of whether the stakeholders involved in the process are institutional (e.g. representatives of sectors, decisionmakers and politicians) or informal (e.g. residents and NGOs), it is necessary to comprehensively examine their role and the options for their inclusion. Stakeholders have different needs and special features, which is why the methods for obtaining their opinion must be sufficiently flexible.

The availability of stakeholders depends on the time the discussions are taking place (e.g. institutional stakeholders can attend the workshops during business hours, whereas residents can usually only attend them outside their work time) and the method of collecting information (workshops are more suitable for the elderly, whereas young people prefer to communicate through online surveys and social networks). Inappropriate times and methods may result in unbalanced answers and inappropriate measures.

An additional problem can also be caused by a large number of answers and especially their diversity. This can be prevented by starting the participatory process early, in which common goals and needs are first identified and the mechanisms for seeking common points are jointly agreed. It is necessary to very clearly define the goals and limitations of the participatory process to facilitate moderated discussion and limit the stakeholders' expectations. This makes it possible to build the required trust.

Because the areas and stakeholders differ from one another, the participatory process must always be adapted to the local context. The questions must also be selected well. The information provided must be clear and understandable to all participants. The selected space, time and method of inclusion must be adapted to 
various groups, but because individual groups nonetheless do not respond they need to be approached personally, in their own environment.

It makes sense to start the participatory process on the broadest possible basis, by including as many residents/stakeholders as possible. By formulating or selecting goals, the number of participants gradually shrinks to the most relevant ones. Especially with larger groups, the number is reduced to the representatives of a particular group (e.g. a society or association) and the methodology changes as well (e.g. switching to focus groups).

The participation of certain key stakeholders, such as politicians, public administration, experts and planners, is taken for granted considering their roles in the planning process. These roles differ, but as key stakeholders they have to be informed of the entire process in a timely manner, so they can plan to take part. Because their roles overlap it is often difficult to establish who directs the participatory process, and therefore, the roles of every key stakeholder must be clearly defined. A gap often occurs between the politicians' desires and expectations on the one hand and the roles and expert expectations of planners and specialists on the other. The specialists' role is to propose feasible solutions that agree with the needs and laws, and rely on professional expertise, whereas the role of the politicians is to take responsibility and select the most suitable solution. Politicians play an especially vital role when it comes to demanding and sensitive measures when in addition to making decisions they are responsible for providing suitable information to the public about the decisions adopted. In turn, with minor technical measures, their role is smaller, and their involvement is often not even required. With demanding processes, politicians must be involved the entire time, so they have all the background information they need to make the final decision.

Key actors also include the media, which are not stakeholders per se, but represent the voice of the stakeholders. They can inform people of the participatory process and occasionally even stimulate it, whereas on the other hand, they also elucidate the topics addressed by the participatory process.

Especially great attention should be dedicated to those stakeholders that can articulate their expectations very clearly and thereby overshadow other stakeholders. In addition, it is necessary on the one hand to limit the influence of stakeholders that wish to promote only their narrow interests and, on the other, to enhance the role of reserved and less qualified stakeholders, especially those from vulnerable groups, so they can also be involved in the process and express their opinion. Vulnerable groups include the disabled, unemployed, children, older people, the financially challenged, immigrants and so on. Cooperation should be adapted to their capabilities and abilities, including by selecting appropriate methods. They can be involved through their representatives and suitably informed through various media.

In carrying out the participatory process, one should be aware that it usually takes a long time and that several planning processes take place in parallel where frequent stakeholder participation is expected. Consequently, all the steps must be well-thought-out because a broad inclusion of stakeholders does not always make sense, especially because the goal is to maintain the stakeholders' interest over a longer period of time. 
Even though participatory planning can be a long and expensive process, it saves a lot of time and energy during implementation. If stakeholders are not suitably involved, they may raise their voice later on, slowing down or even stopping the implementation of the adopted decisions.

This can be prevented with a well-thought-out process of including various stakeholders, which requires highly qualified specialists and good command and development of various inclusion methods. Great emphasis must also be placed on informing the public and raising its awareness. The media play an especially important role in this.

It is understandable that due to financial limitations and incompatibility, not all stakeholder proposals can be adopted. Therefore, it is vital how various information is filtered and the final decision is adopted. Certain more demanding decisions are taken by qualified experts, whereas with others, in which the public is also involved, the process must be transparent throughout and the participants must be informed in a timely manner of their roles and the influence they will have on the final decision. A neutral group of experts can help in selecting the right proposals and reliable analyses of the current state can be of great help, but in any case, the initiators must be informed of the decisions as they are adopted.

Despite good intentions, the participatory process results cannot always be realized in practice. Sometimes, the delay in applying the adopted decisions is only temporary (e.g. because of insufficient funds), but because of the participatory process taking so long the circumstances influencing the beginning and management of the process in its early stage often change as well. A delay usually requires just a little patience, whereas not observing the measures adopted demands an explanation. Communication and information must be convincing and truthful, and they must convey realistic reasons for the situation because only this way the participants in the process can maintain their trust in the participatory process providers. To avoid major complications, this must already be drawn attention to during the implementation of the participatory process, and it is vital not promise too much, which is often the case when politicians are also involved in the process.

A similar problem occurs when the participatory process involves unattractive, but necessary measures. The success of communicating such measures depends on the trust in experts and planners, as well as on how they are presented. Attention must be brought to the basic goal that will be achieved through this measure and, most importantly, consent must be obtained from key stakeholders (e.g. experts and politicians). In addition, it is necessary to plan long-term and build on a group of several interrelated measures that lead to achieving a common goal. Although true, clear and objective information is the most important, it is also possible to come out first with an even less popular measure and then reach a mutually agreed solution as originally planned. Sometimes, it is important not to give an option of accepting or rejecting the measure but to only let the public select between variants of the same unpopular measure.

However, the public attitude towards the participatory process and the consequent inclusion in it depend not only on the subject addressed but also on the territorial level. The public feels closer to concrete, local projects, in which they are familiar 
with the issue at hand, whereas they respond more poorly to more abstract strategic topics and documents that involve the regional or national level. In more complex matters, the public lacks the required expertise and thus it is also not capable of contributing to proposals. Therefore, in these cases participation focuses primarily on institutional stakeholders, experts that are familiar with the issue, and highly qualified representatives of various target groups (e.g. NGOs). At a higher territorial level, the number of potential stakeholders increases, and the methods must be adapted to this (e.g. online surveys instead of workshops for residents).

Because the implementation of the participatory process in different circumstances and at different territorial levels can vary in the degree of difficulty, substantial efforts should be directed to selecting qualified facilitators and proven and adjusted methods. The facilitators must be highly qualified, familiar with the conditions, communicative and socially sensitive. They must be trustworthy and neutral individuals that can listen to various arguments, seek common points and prevent conflicts. They must have a good command of various methods, which they must adapt to an individual process or an individual stakeholder group. Despite being highly qualified, they must adapt their manner of expression to the participants, so that everyone can understand them and can present their own opinion during the participation process. This makes participation a learning process that changes the mindsets of the public, politicians, planners and experts.

\subsection{Discussion}

This study comprehensively dealt with participatory transport planning in eight selected European metropolitan regions. It was based on the experience of experts that completed the questionnaires and shared their experience at a workshop. The focus was on the participatory process as such rather than its comparison between individual metropolitan regions or the special features of participatory transport planning.

As expected, a stronger participation culture can be ascribed to the Scandinavian metropolises, which is most likely the result of both external factors (legal framework, political readiness, governance structure and role of planners) and internal factors (public awareness, social capital, economic conditions; Swapan 2014). This can be linked to the power relationship between decision-makers, where the degree of involvement of others depends on an individual responsible person or institution (Arnstein 1969; Cleaver 1999; Pütz 2011; Pacione 2014) and to the level of democracy in a society (Cleaver 1999; Abels 2007; Pacione 2014). In contrast to southern European countries, the policy of Scandinavian countries tends to be more consensual. They have a longer tradition of inter-party cooperation and, according to the stakeholders attending the workshop, they also have a longer tradition of carrying out participatory processes, which is a prerequisite for acquiring suitable expertise, resources and learning abilities (Sarzynski 2015). 
Like in the case of spatial planning in the Alpine countries (Nared et al. 2015), this study also shows that participation is incorporated into the legislation and planning systems (Pacione 2014), but it maintains a pro forma character (Nared et al. 2015). According to Hong (2018, p. 202), this type of participation is only a formality and it is basically not utilized to obtain the residents' opinion. In addition, Sagaris (2014) argues that despite its recognized benefits for transport planning, participation remains at a ritual level.

Higher expectations in incorporating participation into planning (using the case of green infrastructure) were also voiced by Bissonnette et al. (2018), who determined that participation is often narrowed down to paid professionals and focuses less on resident participation. Like here, they established that the sectors do not connect enough with one another (silo effect) and that they only focus on one sector instead of integral planning.

As a rule, the law limits participatory planning to formal comments and public disclosures, and planners often do not wish to engage in more than that because they perceive it as extra work (Swapan 2014). The stakeholders' arguments against extensive inclusion of the public are the long duration and high cost of the participatory process, but they agree with various authors (Sayce et al. 2013; Sagaris 2014) that including residents in planning, implementation and evaluation simplifies many processes. Such participation increases the legitimacy and quality of decisions and ownership; other positive effects include more sustainable and supportable decisions that reflect community values, agency credibility and faster implementation of plans and projects (Sagaris 2014). This way participation contributes to robust projects or, according to Hong (2018), the quality of projects is more important than their speed or cost.

Despite many identified advantages of participatory planning, Chatty et al. (2003) make the important point that the transformation from an authoritarian and technocratic style of management to participatory and inclusive approaches is a demanding task, in which the planners' reservation is not the result of a lack of willingness to carry out participatory processes, but a lack of qualification and a lack of or unfamiliarity with suitable methods. On the other hand, faster development hinders even relatively little interest from the residents (Swapan 2014).

A need for faster development of and better familiarity with participatory methods is also indicated by the findings of this study, in which stakeholders primarily identified the need for the development of ICT tools. According to Hong (2018), the selection of methods is key for reaching the widest possible range of residents, whereby the methods employed must be able to capture and promote the residents' knowledge and awareness (Sagaris 2014; Swapan 2014).

Information technology opens up numerous possibilities, from setting up the necessary communication channels (Nared and Visković 2012), remote access, online GIS, 3D models and so on (Hanzl 2007).

Even though all the stakeholders in the participatory process must strive for a strong sense of community (Hong 2018), it should be noted that every stakeholder group has its own tasks and expectations, which is why they never fully advocate shared interests, but seek to reach their own goals and convince others with their argu- 
ments (Pütz 2011). The stakeholders included in this study were aware of this and hence they placed a greater emphasis on an individual stakeholder group and its role in the process, clearly highlighting the role of politicians, planners, public administration and residents. These stakeholders differ in terms of financial resources, available information and expertise, which are especially problematic because planning is very demanding and includes legal, administrative, technical, and political elements. Wealthier and well-connected investors and decision-makers may obtain expert opinions and exploit the governance structures to achieve their own interests, whereas the residents are left to their own knowledge and abilities (Pacione 2014; Sarzynski 2015). Similarly, Swapan (2014) argues that involvement in the participatory process is influenced by the economic condition, awareness of the planning process, effectiveness of communication strategies taken by the planning agency, trust in planning agency, sense of urgency and status of social capital.

Therefore, in addition to the role of politicians as key decision-makers, the role of planners is especially important. Their experience, expertise and good knowledge of laws and the field itself must build a bridge between various types of stakeholders. According to Nostikasari (2015, p. 107), planners can ensure "mutual learning between the expert-based knowledge and experience-based knowledge". They should provide expert knowledge to the public administration representatives and, together with them, also enhance the participation of organizations whose expertise can help the residents. They can also approach the residents directly, using communication to imprint a sense of ownership on them and help them develop the skills to engage in autonomous participation (Hong 2018).

As already described at the beginning of this chapter, resident participation is vital especially because of their practical experience, because they recognize the needs of the local area (Hong 2018), and also because they can provide "alternative policy-oriented knowledge by not only considering rational behaviour patterns but also personal motives and reflections on key issues such as workplace or residence selection" (Delclòs-Alió and Miralles-Guasch 2017, p. 172). It is important to include all resident groups because every group has a different experience, and the exclusion of one from planning can lead to long-lasting neglect and the consequent long-term social exclusion of some residents (Nostikasari 2015). Workshop participants thus highlighted the necessity to include all vulnerable groups, either directly or through representatives. This is especially important in terms of public transport, which is often the only form of mobility among vulnerable groups and something that the level of an individual's social inclusion depends on (Nostikasari 2015; Özkazanç and Sönmez 2017).

Despite acknowledging the importance of including all stakeholders, especially residents, in contrast to Sagaris (2014), the workshop participants did not see residents in the role of planners, but more as a group whose knowledge can substantially contribute to the quality of the decisions and plans adopted.

Because of an increasing need for the participation of residents, whose time is usually limited, it is vital to approach it prudently in order not to burden residents too much and, most importantly, to present the advantages of participation to them. 
According to Geoghegan et al. (2004), sometimes planners even deliberately overuse participation to make the residents inert or divert their attention from certain issues.

Sarzynski (2015) argues that the intensity of stakeholder participation is influenced by their satisfaction with the results achieved. In contrast, Hong (2018) believes that satisfaction results in more from the feeling of having influenced the decisions than reaching one's goals. The workshop participants went even a step further, establishing that trust in the planners or experts and the expectation that the results will in fact be included in the plan are crucial for resident participation and the resulting success of measures. This agrees with Swapan (2014), who argues that trust in planners is crucial for citizen participation and that a lack of it discourages residents from participating, adding that a lower degree of resident participation does not reflect the residents' ignorance, but their response to negative experience in the past.

This shows the need for well-qualified planners and facilitators that must be wellacquainted with the situation and well-versed in methods. To avoid a negative experience, planners must reflect on and prepare their interventions well before starting to work with stakeholders (Dionnet et al. 2013). Especially great emphasis should be placed on the selection of methods because the stakeholders' time is limited.

However, as indicated by the results of this study, in addition to the factors listed above, stakeholder inclusion in the participatory process depends strongly on the level at which an individual plan is being prepared. At the local level, the residents' experience-based knowledge may suffice for them to participate in the process (Bole et al. 2017), whereas with more complex plans or a higher territorial level, this is no longer the case; therefore, lower participation is understandable and tends to shift from an individual to the representatives of specific groups.

Even though the workshop with the representatives of the metropolitan regions was based on the practical experience of planners, experts and the representatives of public administration (i.e. regions) rather than scholarly discussions, the entire process yielded completely comparable findings. Moreover, individual authors focused only on specific aspects of participation and the participatory process, whereas the results achieved through participatory research provided a relatively comprehensive overview of the topics discussed in the articles. This again shows the importance of including relevant stakeholders as providers of experience-based knowledge, in which, compared to other studies, the workshop participants adopted a critical stance, even though they were actually evaluating their own work.

\subsection{Conclusions}

This chapter provides a comprehensive overview of findings on the role of participation in transport planning in eight European metropolitan regions that were obtained through an analysis of a questionnaire on the strengths, weaknesses and needs identified in the metropolitan regions, an in-depth questionnaire on various aspects of participatory transport planning and an international workshop attended by over fifty experts, planners and public administration representatives. 
It was determined that the culture of stakeholder participation in planning varies between the metropolitan regions, in which the Scandinavian metropolises stand out as the best. In general, what all the metropolitan regions have in common is that participatory planning remains an underused potential, which only rarely extends beyond the legally prescribed requirements.

Another important finding is that various types of stakeholders (politicians, planners, public administration and residents) play various roles in the participatory process and that they must know their role well, otherwise the interests of financially stronger stakeholders, who can obtain suitable expert opinions and expertise, predominate. Planners play the key role here: through their expertise and experience, they must ensure suitable participation of all groups and thus contribute to highlighting joint interests.

The inclusion of various stakeholders must be prudent, which requires highly qualified facilitators, a good command of the required methods and sufficient information and awareness raising.

At the very beginning of the process, it is vital to highlight its purpose and potential limitations and explain how the results will be included in the plans. This limits the (potentially too high) expectations of the participants and also provides some justification if the results of the participatory process cannot the fully enforced in the plan for financial or other reasons. In this case, it is necessary to honestly, truthfully and clearly present the reasons for the situation.

It is important to be aware that the involvement in the participatory process and the acceptability of the plan largely depend on the trust between the participants and the planner. This trust can be maintained by including the decisions adopted in the process into the plans, using well-thought-out participation methods, and through work that convinces participants that they can influence the decisions.

The participatory process must be tailored to the concrete conditions both in terms of the participating stakeholders, the methods used and the intensity of participation because sometimes more frequent stakeholder participation is required and sometimes none at all.

The differences in participation across various territorial levels are especially important in this regard. At the local level, the projects are usually concrete and easy to understand, resulting in high resident participation, whereas at higher territorial levels or in more complex projects, the participatory process is based primarily on highly qualified institutional stakeholders and the representatives of individual resident groups.

The key finding is that despite being time-consuming and financially demanding, the participatory process is an important planning tool, which, although it demands more energy during the preparation stage, enables easier and faster implementation because the measures are coordinated among the key stakeholders. The prerequisites for the effective implementation of participatory processes and participatory planning are suitably selected methods and highly qualified planners on the one hand, and the political will on the side of the decision-makers to actually allow stakeholders to influence decisions on the other. 
Acknowledgements The author acknowledge the financial support from the Slovenian Research Agency research core funding Geography of Slovenia (P6-0101) and from the European Regional Development Fund funding SMART-MR (Interreg Europe Programme). The author would also like to thank project partners and workshop participants for their valuable contributions.

\section{References}

Abels G (2007) Citizen involvement in public policy-making: does it improve democratic legitimacy and accountability? The case of pTA. Interdisc Inform Sci 13(1):103-116. https://doi.org/10.4036/ iis. 2007.103

Arnstein SR (1969) A ladder of citizen participation. J Am Inst Planners 35(4):216-224. https:// doi.org/10.1080/01944366908977225

Bickerstaff K, Walker G (2002) Shared visions, unholy alliances: power, governance and deliberative processes in local transport planning. Urban Stud 42(12):2123-2144. https://doi.org/10.1080/ 00420980500332098

Bickerstaff K, Walker G (2005) Participatory local governance and transport planning. Environ Plann A 33:431-451. https://doi.org/10.1068/a33173

Bissonnette JF, Dupras J, Messier C, Lechowicz M, Dagenais D, Paquette A, Jaeger JAG, Gonzalez (2018) Moving forward in implementing green infrastructures: stakeholder perceptions of opportunities and obstacles in a major North American metropolitan area. Cities 81:61-70. https://doi. org/10.1016/j.cities.2018.03.014

Bole D, Šmid Hribar M, Pipan P (2017) Participatory research in community development: a case study of creating cultural tourism products. AUC Geographica 52(2):164-175. https://doi.org/ 10.14712/23361980.2017.13

Chatty D, Baas S, Fleig A (2003) Participatory processes towards co-management of natural resources in pastoral areas of the Middle East: a training of trainers source book based on the principles of participatory methods and approaches. FAO, Rome and Palmyr

Cleaver F (1999) Paradoxes of participation: questioning participatory approaches to development. J Int Dev 11:597-612

Delclòs-Alió X, Miralles-Guasch C (2017) Suburban travellers pressed for time: exploring the temporal implications of metropolitan commuting in Barcelona. J Transp Geogr 65:165-174. https://doi.org/10.1016/j.jtrangeo.2017.10.016

Dionnet M, Daniell KA, Imache A, von Korff Y, Bouarfa S, Garin P, Jamin JY, Rollin D, Rougier JE (2013) Improving participatory processes through collective simulation: use of a community of practice. Ecol Soc 18(1):36. https://doi.org/10.5751/ES-05244-180136

Eltis (2014) Guidelines. Developing and implementing a sustainable urban mobility plan. European Commission, Brussels

Geoghegan T, Renard Y, Brown NA (2004) Guidelines for participatory planning: a manual for Caribbean natural resource managers and planners. Caribbean Natural Resources Institute, Barataria

Hanzl M (2007) Information technology as a tool for public participation in urban planning: a review of experiments and potentials. Des Stud 28:289-307. https://doi.org/10.1016/j.destud.2007.02. 003

Hong Y (2018) Resident participation in urban renewal: focused on Sewoon renewal promotion project and Kwun Tong Town Centre Project. Front Architectural Res 7:197-210. https://doi.org/ 10.1016/j.foar.2018.01.001

Jacob J (1961) Death and life of great American cities. Random House, New York

Nared J (2016) The interplay of institutional actors for achieving better governance of metropolitan regions. In: Knowledge, policymaking and learning in European metropolitan areas: experiences 
and approaches. Geography of Research in Europe and Territorial Policy Innovation, GREAT PI, Brussels, 25-26 Jan 2016

Nared J (ed) (2019) Transforming European metropolitan regions. Smart mobility for better liveability. Založba ZRC, Ljubljana

Nared J, Razpotnik Visković N (eds) (2012) Moving people: towards sustainable mobility in metropolitan regions. Joint Spatial Planning Department Berlin-Brandenburg, Potsdam

Nared J, Razpotnik Visković N, Cremer-Schulte D, Brozzi R, Cortines Garcia F (2015) Achieving sustainable spatial development in the Alps through participatory planning. Acta Geogr Slov 55(2):363-373. https://doi.org/10.3986/AGS.1631

Nostikasari D (2015) Representations of everyday travel experiences: case study of the Dallas-Fort Worth Metropolitan Area. Transp Policy 44:96-107. https://doi.org/10.1016/j.tranpol.2015.06. 008

Özkazanç S, Sönmez FNÖ (2017) Spatial analysis of social exclusion from a transportation perspective: a case study of Ankara metropolitan area. Cities 67:74-84. https://doi.org/10.1016/j. cities.2017.04.013

Pacione M (2014) The power of public participation in local planning in Scotland: the case of conflict over residential development in the metropolitan green belt. GeoJournal 79:31-57. https://doi. org/10.1007/s10708-013-9477-y

Planning Democracy (2012) Re-valuing public participation in Scotland's planning system. Advocacy paper. Edinburgh, p 7

Pütz M (2011) Regional environmental governance: interdisciplinary perspectives, theoretical issues, comparative designs (REGov) power, scale and Ikea: analysing urban sprawl and land use planning in the metropolitan region of Munich, Germany. Proc Soc Behav Sci 14:177-185. https://doi.org/10.1016/j.sbspro.2011.03.034

Rahman AU (2016) Urban sustainability through strategic planning: a case of metropolitan planning in Khulna city, Bangladesh. J Urban Manage 5:16-22. https://doi.org/10.1016/j.jum.2016.06.001

Sagaris L (2014) Citizen participation for sustainable transport: the case of "Living City" in Santiago, Chile (1997-2012). J Transp Geogr 41:74-83. https://doi.org/10.1016/j.jtrangeo.2014.08.011

Sagaris L (2018) Citizen participation for sustainable transport: lessons for change from Santiago and Temuco, Chile. Res Transp Econ 69:402-410. https://doi.org/10.1016/j.retrec.2018.05.001

Sarzynski A (2015) Public participation, civic capacity, and climate change adaptation in cities. Urban Climate 14:52-67. https://doi.org/10.1016/j.uclim.2015.08.002

Sayce K, Shuman C, Connor D, Reisewitz A, Pope E, Miller-Henson M, Poncelet E, Monié D, Owens B (2013) Beyond traditional stakeholder engagement: public participation roles in California's statewide marine protected area planning process. Ocean Coast Manage 74:57-66. https://doi.org/10.1016/j.ocecoaman.2012.06.012

Swapan MSH (2014) Realities of community participation in metropolitan planning in Bangladesh: a comparative study of citizens and planning practitioners' perceptions. Habitat Int 43:191-197. https://doi.org/10.1016/j.habitatint.2014.03.004

Open Access This chapter is licensed under the terms of the Creative Commons Attribution 4.0 International License (http://creativecommons.org/licenses/by/4.0/), which permits use, sharing, adaptation, distribution and reproduction in any medium or format, as long as you give appropriate credit to the original author(s) and the source, provide a link to the Creative Commons licence and indicate if changes were made.

The images or other third party material in this chapter are included in the chapter's Creative Commons licence, unless indicated otherwise in a credit line to the material. If material is not included in the chapter's Creative Commons licence and your intended use is not permitted by statutory regulation or exceeds the permitted use, you will need to obtain permission directly from the copyright holder.

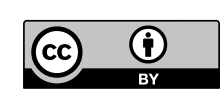

